\title{
Application of Electrodialysis in Waste Water Treatment and Impact of Fouling on Process Performance
}

\author{
Mohsan Akhter, Ghulam Habib* and Sana Ullah Qamar \\ Department of Chemical Engineering, National University of Science and Technology, Islamabad, Pakistan
}

\begin{abstract}
Electrodialysis (ED) is a new advanced separation process that is commonly utilized for producing drinking water from water bodies as well as for the treatment of industrial effluents. ED process is applied on commercial scale. Basically, an ED process consists of an ion exchange membrane and the diving force necessary for applicability of the process is electric potential. Due to the presence of electric potential ions from one solution after passing through ion selective membrane barrier are transferred to another solution. The main factors on which ED process performance depends on concentration of ion in raw water, flow rate, concentration of feed, current density, membrane properties and cell compartments geometry.

Fouling which is produced by foulants including organics, colloids and biomass on the inside membrane internal structure or on the outside surface results in reduction of process separation efficiency and energy consumption is enhanced. Fouling increases the membrane resistance and selectivity of membrane is reduced by fouling. Therefore, some methods are proposed to reduce fouling in ED system such as pre-treatment of feed solution, zeta potential control, membrane properties modification and flowrate optimization. It is a need of an hour to suggest a reducing method less energy and thus minimum operating and investment cost. Electrodialysis Reversal (EDR) system can be as regarded as best option because no extra chemicals are required and life of membrane increased by it. In EDR fouling progress is broken by revering electric potential (applied electric field). This paper elaborates ED process briefly and presents an overview of literature review on different kinds of fouling mechanisms. Also, different cleaning methods have been briefly described for enhancing efficiency of ED process.
\end{abstract}

Keywords: Wastewater; Fouling; Permselectivity; Ion exchange membrane

Abbreviations: ED: Electrodialysis; EDR: Electrodialysis reversal; TDS: Total Dissolved Solid; BPM: Bipolar Membrane

\section{Introduction}

The population of world is increasing day by day and natural water resources have been found insufficient to meet the demand of fresh water. Water scarcity could be the global risk for next decades if steps will not be taken for the reclamation of waste water. Method of waste water treatment is chemical coagulation, biological degradation, electrochemical methods, adsorption and membrane. Among these techniques membrane technology has been found significant because of treated water quality. Membrane is defined as a selective barrier between two phases and it can be formed from natural and synthetic material including organic and inorganic polymer, ceramic and metal material. Separation depends upon pore size [1].

ED process is basically a membrane separation process and it is commonly used for the treatment of waste water (Figure 1) [2]. In ED electric potential is used as a driving force and ion exchange membrane is applied between anode and cathode. On the application of electric current negative and positive ions are moved towards the respective electrodes based on their polarity. Cations are passed though the compartment containing membrane having negative charge and vice versa for anions. The compartments are diluted and concentrated in alternative way. The performance of an ED process depends upon following parameters current density, $\mathrm{pH}$, flow rate, ED cell structure, feed water ionic concentration, properties of ion exchange membrane. Membrane fouling is an important factor that results in enhancement of energy consumption and decline of membrane flux. Selectivity of membrane is adversely reduced. Fouling is caused by the deposition of biomass, colloid and organics substances. Accumulation could be happened on the inside or on the outside surface of membrane. As most of collides presents in water are negatively charged so most of the research is carried out on anion exchange membrane fouling [3].

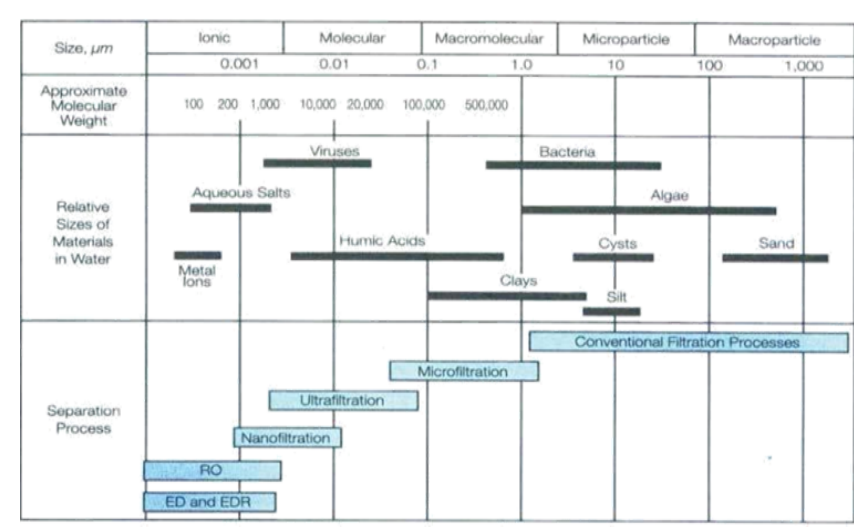

Figure 1: Membrane process

*Corresponding author: Ghulam Habib, Department of Chemical Engineering National University of Science and Technology, Islamabad, Pakistan, E-mail: ghabib.che5@scme.nust.edu.pk

Received April 16, 2018; Accepted May 21, 2018; Published May 28, 2018

Citation: Akhter M, Habib G, Qamar SU (2018) Application of Electrodialysis in Waste Water Treatment and Impact of Fouling on Process Performance. J Membr Sci Technol 8: 182. doi: 10.4172/2155-9589.1000182

Copyright: $\odot 2018$ Akhter M, et al. This is an open-access article distributed under the terms of the Creative Commons Attribution License, which permits unrestricted use, distribution, and reproduction in any medium, provided the original author and source are credited. 


\section{Working principle of ED system}

The main objective of ED process is removal of salts from aqueous solution by passing an aqueous solution through an ion exchange membrane (Figure 2) [4]. The cell is divided into compartments by placing anion and cation exchange membrane between two electrodes acting a cathode and anode. Direct current is applied between two electrodes. Consider feed solution containing sodium chloride passes through ED system and focus on one compartment. Cations pass through cation exchange membrane and anions are restricted. Anion could only pass through anion exchange membrane which restricts passage of cations. The concentration of salts decreases in this compartment but salt concentration keeps increasing in the adjacent compartment. Thus, salt concentration decreases in alternative compartments and enhances in the rest. Both desalinated water and concentrated brine leave from the adjacent compartments. Applied electric potential acts as driving force for ED process.

ED is preferred when salt concentration is low and it regarded as an energy efficient process. The electric current requirement depends upon number of ions transported through ion exchange membrane.

Electric current required $=\mathrm{Z} \times \mathrm{F} \times \mathrm{Q} \times \Delta \mathrm{C} / \mathfrak{E}$

Where, $\mathrm{Z}=$ Charge on ion; $\mathrm{F}=$ Faraday's constant; $\mathrm{Q}=$ Feed solution flow rate; $\Delta \mathrm{C}=$ Change in solute concentration; $\mathfrak{E}=$ Current utilization factor that accounts for energy efficiency.

ED processes have been used widely on commercial scale and various applications of ED systems have been shown in Table 1 [5].

ED process was first time used by Maigrot and Sabates for demineralizing sugar syrup in 1890 (Figure 3) [6]. Wood was used to manufacture frame of ED system. Anode and cathode were formed by carbon and permanganate paper was used to make ion exchange membrane. In order to provide electric current dynamo was used. The syrup solution was poured through anodic compartment and anode was placed in middle of the system. On the application of electric potential cations such as sodium, magnesium and calcium were transferred through anodic region to cathodic region. Demineralized syrup was obtained in anodic compartment [6].

Removal of copper ions by the application of ED system was study by [3]. In order to achieve copper ions removal two different ion exchange membranes were used. Following parameters were determined initial copper ions concentration, $\mathrm{pH}$, flow rate, conductivity of solution. At the value of $7.5 \mathrm{~V}$ applied voltage and concentration of copper initially present $4 \mathrm{~g} / \mathrm{L}$ the percentage of copper ion removal greater than $85 \%$ was obtained. The effect of temperature, voltage and flow rate on the performance of ED system used for lead removal was studied [7]. It was reported that cell performance enhanced by increasing voltage and temperature but decrease in separation percentage was revealed by increasing flow rate.

ED process can be used for the removal dissolved solid having charge on their surface by the application of ion exchange membrane. The membrane used for cations transfer is called cation exchange membrane and it restricts anions. The function of anion exchange membrane is vice versa to cation exchange membrane. The thickness of membrane is 0.1 to 0.6 and based upon morphology membrane could be homogeneous or heterogeneous. The ion exchange membrane is made by making blend of ion exchange resin with polymer and ion exchange must have at least half of polymer mixture. Some of the important features that are essential for cation or anion exchange membrane are ion exchange membrane must have low electrical resistance, it should show insolubility in aqueous solution, membrane must have long life expectancy, it can be used above $46^{\circ} \mathrm{C}$, semi rigidity for ease of handling, membrane should be available in different sizes and configurations. 50$99 \%$ removal of source water pollutants or dissolved solids could be achieved by ED process [8]. Total Dissolved Solid (TDS) can be treated and production of water less than $10 \mathrm{mg} / \mathrm{L}$ TDS is achieved by ED system when water salinity in the range of 100 to $1200 \mathrm{mg} / \mathrm{L}$. The main advantage of ED process is no phase change takes place, no additional chemical requirement, high perm selectivity, low electrical resistance, high mechanical and chemical stability, some industrial applications of ED process have been depicted in Table 2 [5].

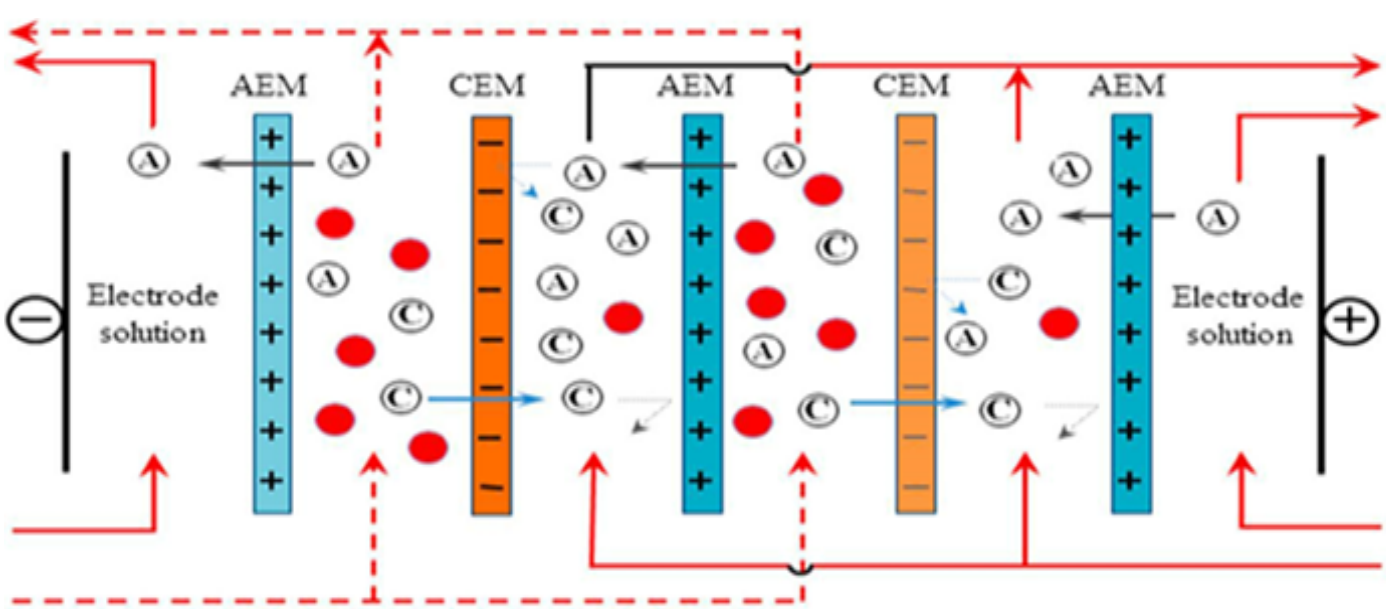

Neutral molecules; C Cations; (A) Anions; - Concentrating cell; - - Desalination cell; CEM: Cation exchange membrane; AEM: Anion exchange membrane;

Figure 2: Basic principle of electrodialysis. 


\begin{tabular}{|l|l|}
\hline Processes & Applications \\
\hline Electrodialysis & Used for water desalination and salt pre-concentration \\
\hline Donnan dialysis & For water softening \\
\hline Reverse ED & For generating electro dialytic energy \\
\hline Diffusion dialysis & For recovering acid and base \\
\hline Capacitive deionization & It is used for water desalination and water softening \\
\hline
\end{tabular}

Table 1: Applications of processes related to electrodialysis system.

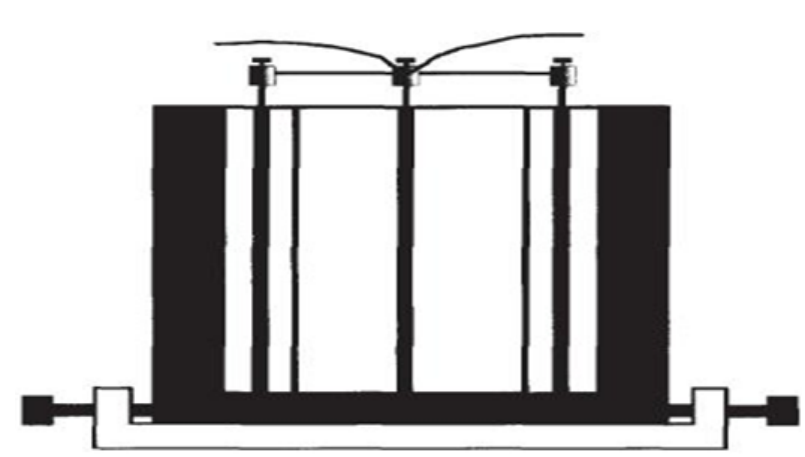

Figure 3: Scheme of first electrodialysis system

\begin{tabular}{|l|l|l|}
\hline Applications & Scale & Major Problems \\
\hline Desalination & Applied commercially & Cost \\
\hline Water treatment process & Applied commercially & Cost \\
\hline Waste treatment & Applied commercially & Fouling of membrane \\
\hline Demineralization of food products & Pilot scale plant & Fouling of membrane \\
\hline Production of table salt & Commercial & Fouling of membrane \\
\hline
\end{tabular}

Table 2: Industrial applications and major problems of ED.

\section{Ion exchange membranes used for ED process}

Depending on the type of ionic groups attached to the membrane matrix, ion exchange membranes are classified into anion exchange membranes and cation exchange membranes.

Negatively charged groups, such as -SO3-, -COO-, -PO32-, $\mathrm{PO} 3 \mathrm{H}-$, - C6H4O-, etc., formed cation exchange membranes which are fixed to the backbone of membrane reject anions while allowing the passage of cation.

Charged groups, such as $-\mathrm{NH} 3+,-\mathrm{NRH} 2+,-\mathrm{NR} 2 \mathrm{H}+,-\mathrm{NR} 3+,-$ $\mathrm{PR} 3+,-\mathrm{SR} 2+$, etc., formed anion exchange membranes which are fixed to the backbone of membrane reject cations while allowing the passage of anions (Figures 4 and 5) $[9,10]$.

\section{Homogeneous ion exchange membranes}

Different techniques are available to blend ionic groups for the preparation of homogeneous ion exchange membranes. On the basis of starting material membrane, they are classified into 3 types $[11,12]$ but the two most commonly used are,

(a) Anionic or cationic exchange groups monomer to form an ion exchange membrane with the help of copolymerization process;

(b) Use polymer film, introduce ionic characters in two ways directly with functional monomer using grafting process or indirectly monomer non-functional grafting with the help of functionalization reaction (Figure 6) [10].

\section{Inorganic-organic ion exchange membranes}

Due to the exceptional properties within single molecule composites inorganic-organic composite materials are very important which enhance the interaction between the two different molecules [13]. In comparison to the refine organic polymer and inorganic materials these materials have extraordinary properties in terms of their mechanical [14] , thermal [15] , electrical [16] , and magnetic properties [17] Organic polymer shows high photoconductivity, efficient luminescence, structural flexibility, convenient processing and even metallic characteristics. High carrier mobilities, band gap tunability, magnetic field range and dielectric properties and stability in terms of thermal and mechanical which is provided by inorganic compounds. The interface attraction between the organic and inorganic components of different material by combining them in different ways new properties also evolve [18-20].

In recent years due to different application of inorganic-organic material with the combination of different composition the use of inorganic-organic material for ion exchange membrane production is increased. For fuel cell separator application of ion exchange membranes prepared from inorganic-organic material in increased due to the high thermal stability [21,22].

\section{Bipolar ion exchange membranes}

Membrane compositions which contain a layer of selective cation (contain fixed negative charges) and a layer of selective anions (contain fixed positive charges) are called Bipolar Membrane (BPM). Separation
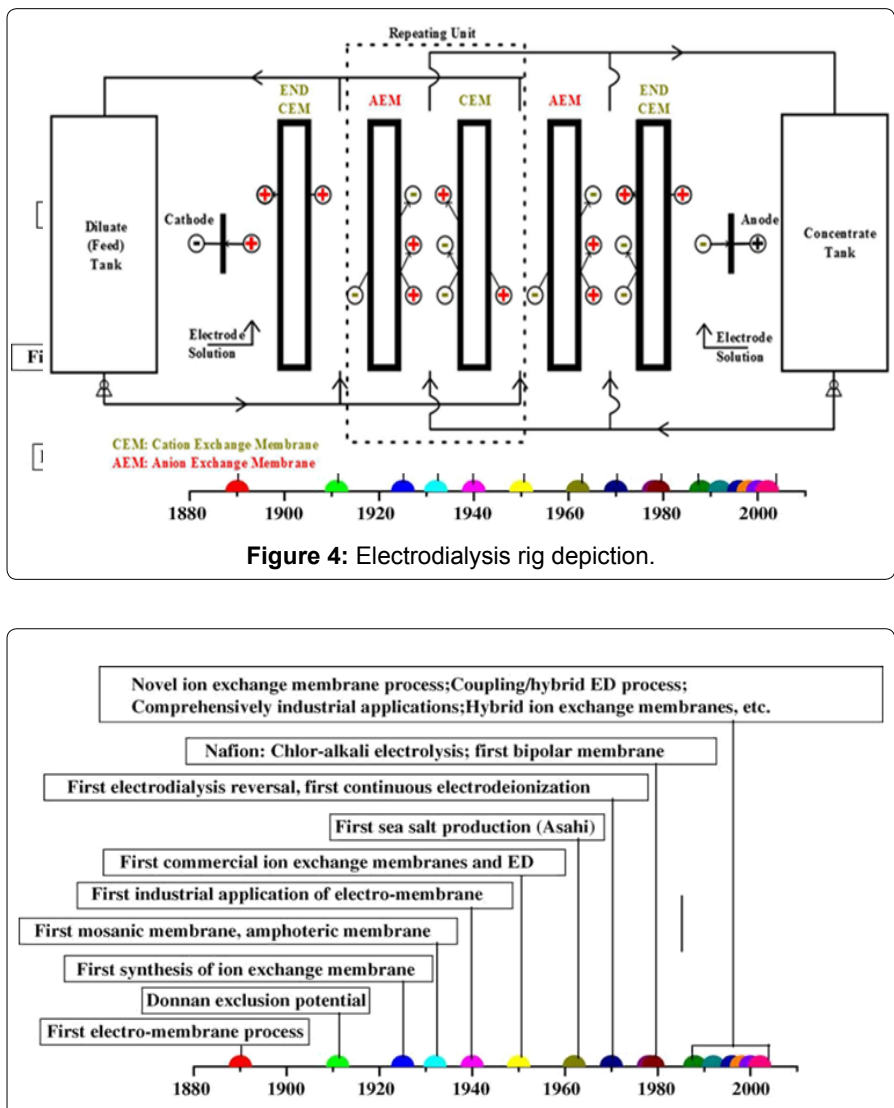

Figure 5: Time line visualization of ion exchange membrane development and their related processes. 
of mono and divalent ions, anti-deposition, anti-fouling, water dissociation, etc. novelties come with the help of composition of anionic and cationic exchange layer [23-25].

Production of acids and bases from the corresponding salts especially for electrodialytic water splitting with the help of BPMs is shown in Figure 7 [26]. This growth point become a very important in many industrial process and daily life technique [24,27]. Conventional technique which contaminates the environment changes with the help of BPM [28].

\section{Amphoteric ion exchange membranes}

Structure in which weak acid (negative charge) and weak basic (positive charge) randomly distributed inside the membrane matrix is called amphoteric ion exchange membranes [29]. Response to the external solution is given by these membranes in term of $\mathrm{pH}$ which shows the charge present on these membranes (Figure 8) [30].

Amphoteric ion exchange membranes were first suggested by $S$ "ollner in 1932 together with mosaic membranes. A lot of research work has been conducted for this type of membrane. The description of ions permeation through amphoteric membrane using a specialized amphoteric membrane model was proposed by Takagi and Nakagaki for describing permeation of ions through and also, they determined charge by amphoteric membrane dissociation.

\section{Permselectivity of cations through membrane having negative charge on the surface}

Permselectivity is an important parameter for evaluating performance of membrane and for cations exchange membrane that

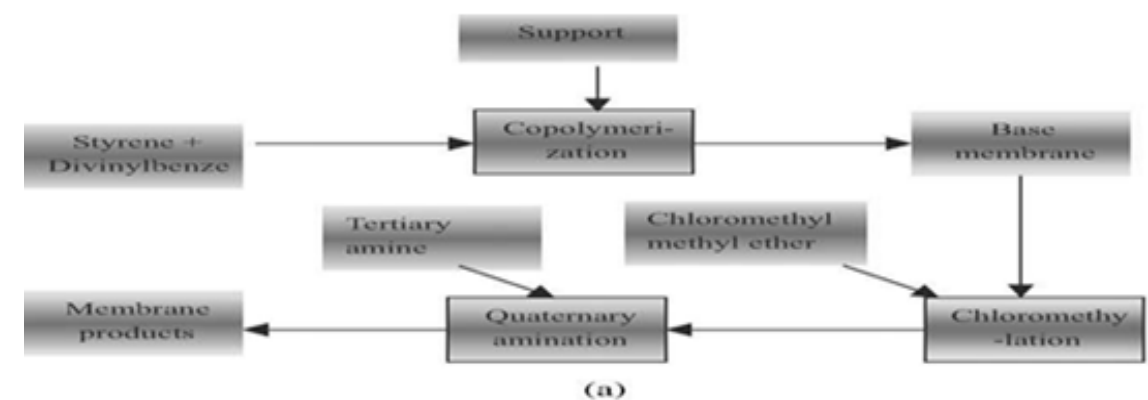

(a)

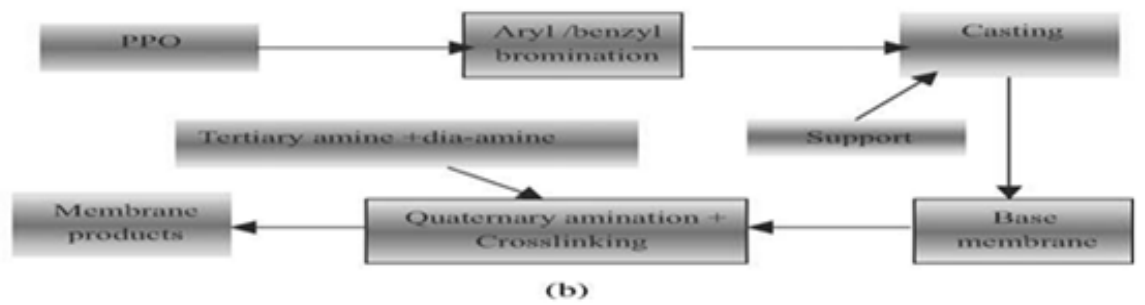

Figure 6: A comparison manufacture route between conventional hydrocarbon type anion exchange membranes and the anion exchange membranes prepared from polymer poly (2,6-dimethyl-1,4-phenylene oxide) (PPO). (a) Route for a traditional hydrocarbon type anion exchange membrane; (b) Route for a new anion exchange membrane prepared from PPO.

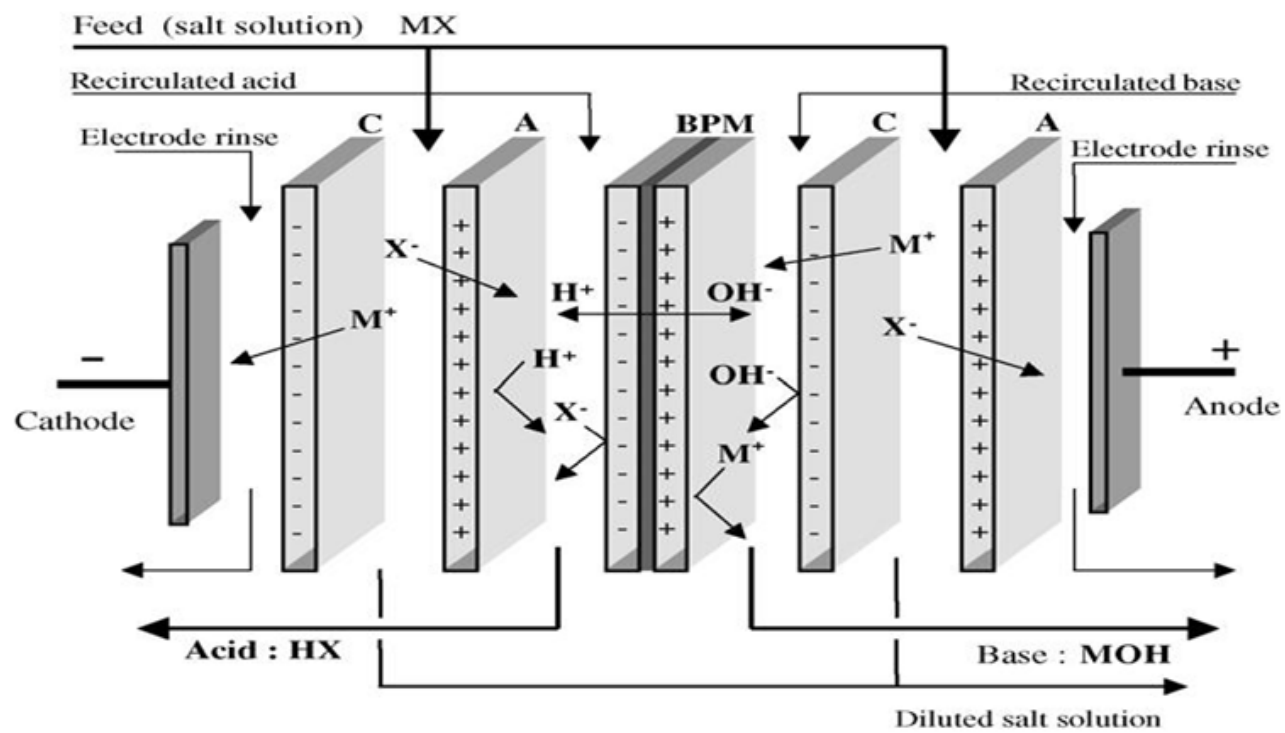

Figure 7: Salt dissociation into acidic and basic ions with bipolar electrodialysis membranes. 


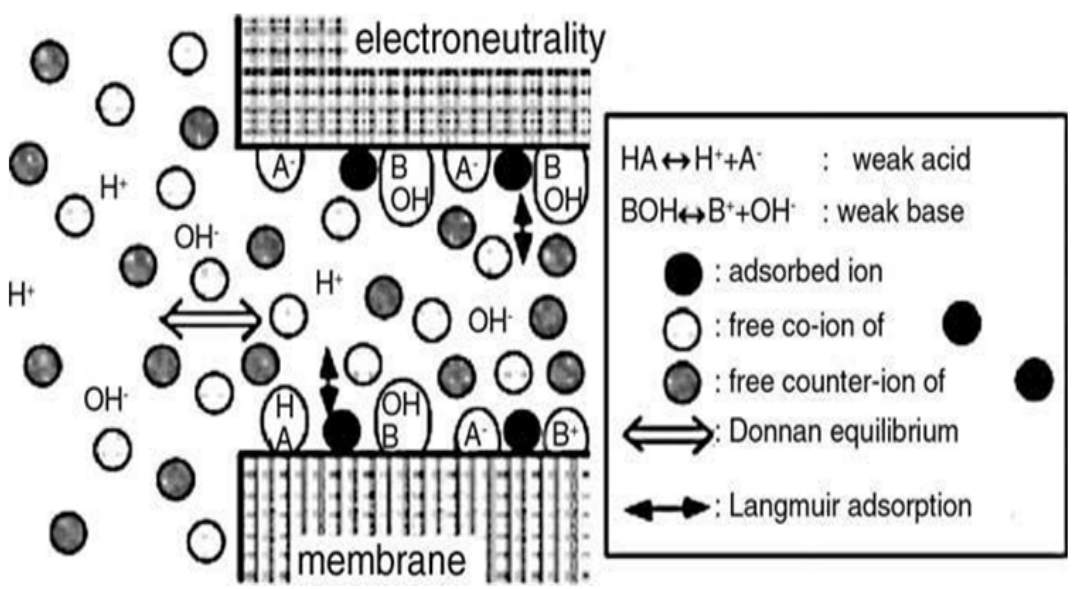

Figure 8: Model for advance amphoteric membrane.

allows passage of cations while restricting passage of anions depends on two parameters:

(1) Relative affinity of cations with membrane;

(2) Difference in migration speeds of cations in selective membrane barrier.

For the sake of simplicity an important ratio of given cation to reference cation (This ratio is termed as permeated equivalent) is calculated and usually $\mathrm{Na}+$ (sodium) ions. $\mathrm{Na}+$ ions are commonly used as reference cation. In order to calculate permselectivity of specified cation, its permeated equivalent value is required.

The required permselctivity between $\mathrm{sn}+$ and $\mathrm{Na}+$ ions is given by following relation:

\section{$\mathrm{P}(\mathrm{S} / \mathrm{Na})=(\mathrm{TS} / \mathrm{TNa}) /(\mathrm{CS} / \mathrm{CNa})$}

TS and TNa are transport numbers symbols of sn+ and sodium ions through selective barrier of membrane while cations concentration is represented by symbol $\mathrm{C}$ on the membrane outside surface of desalting side solution. If the permeated equivalent and transport number of sn+ are represented by Lsi and Tsi,

\section{$\mathrm{Tsi}=\mathrm{Lsi} / 2 \mathrm{kLk}$}

Then eq. 1 will be modified as,

$$
\mathrm{P}(\mathrm{S} / \mathrm{Na})=(\mathrm{LS} \times \mathrm{CNa} / \mathrm{LNa} \times \mathrm{CS})
$$

Lsi can be expressed as the product of mobility of cation sn+ and cation $\mathrm{sn}+$ concentration in membrane phase. Lsi=Usi $\times$ CRsi

Where, Usi $(\mathrm{cm} 2 /($ de/dy $\times \mathrm{s}))=$ mobility of cation; CRsi=concentration of cation. Electrical gradient is depicted by de/dy. On inserting value of Lsi in eq. 2 ,

$$
\mathrm{P}(\mathrm{S} / \mathrm{Na})=\mathrm{Usi} \times \mathrm{CNa} \times \mathrm{CRs} / \mathrm{UNa} \times \mathrm{CRNa} \times \mathrm{Cs}
$$

The relation used for equilibrium constant (KE) between given cation and sodium ions in the membrane phase is given by following equation:

$\mathrm{KE}(\mathrm{S} / \mathrm{Na})=\mathrm{CRS} / \mathrm{CRNa} / \mathrm{CS} / \mathrm{Can}$

Upon inserting eq. 4 in eq. 3 ,

$$
\mathrm{P}(\mathrm{S} / \mathrm{Na})=(\mathrm{Usi} / \mathrm{UNa}) \times \mathrm{KE}(\mathrm{S} / \mathrm{Na})
$$

In this case effect of diffusional boundary layer at membranesolution interface on permselectivity will be completely vanished.

The conditions of diffusional boundary layer that exists on the interface of membrane-solution on the desalting side greatly affect permselectivty and it is generally seen that cations permeation rate that selectively permeated reduces while the permeation rate of cations that are permeated reluctantly increases. This all happened because of compositional changes of cations that takes place on layer from that of bulk solution [31].

\section{Membrane fouling of ED system}

The existence of certain salts layer on membrane surfaces cause to reduce the membrane recovery rate. Fouling potential increases due to the high concentration of salts in ED systems. Through ion exchange membrane the transport of ions increases with the help of electrical current and with time the membrane selective surface precipitation occurs. With the passage of time accumulation on membrane surface increases and a layer is formed called gel layer. As accumulation charge increases in membrane surface precipitation increase and thinner and denser gel layer formed. Restricted ion movement is due to the formation of the gel layer. Foulant and structure of membrane tell the gel layer concentration and electrical resistance. Current efficiency increases due to increase in current density of ED system. The upper value of current density not achieved due to polarization phenomena. Process efficiency decreases due to the high fouling of high current value than limiting current. Blockages are of three types divalent or trivalent ion hydroxides formed, proteins or colloidal substance accumulation on surface, disruption of membrane.

Anionic membranes fouling are due to presence of organic substance humates, organic substances, and dedokosil sodium benzenesulfonate. Cation membranes blockage in surface and inside is due to accumulation of colloidal materials, proteins, and hydroxyl ions. The fouling degree is affected by the chain length which is the physical feature of fouling molecule. Harder fouling is caused by long chain molecules. Adsorbed rate for the surface of membrane is higher and this is due to the less solubility of large molecules. Other parameter which affects the fouling is current density. Rate of fouling is high when the current density is high. The high hydrodynamics pressure drops and decline in flow is due to the presence of suspended solids, silicates, and less soluble substance which is present in wastewater. Membrane 
structures damage physically due to increase to electrical resistance caused by precipitation on the membrane surface.

Increase in concentration caused to increase in membrane fouling if internal membrane fouling control is less. High concentration influences on surface fouling in great. Additional hydraulic resistance is due to protein fouled that can also cause for the formation of gel layer in surface. The waste water treatment of chloralkali industry the presence of calcium and magnesium hydroxide on inside and surface of membrane is reported with the help of studies. Reversible situation achieved due to the precipitation of inorganic salts which yield crystal formation of membrane surface.

Other different compounds which give different precipitation rate of ED process are given below dissolved organic matter, alkaline metals, heavy metals, biomass, organic and inorganic colloids, dissolved gases. Different types of organic solutes effect on the fouling in ED process studies by Lindstrand [32]. Anion and cation selective membrane studied shows that an extraordinary contrast exists between them. A little bit enhancement of cation selective membrane resistance of the meanwhile all solutes fouled the anion selective membranes. This is surely due to the electrostatic attraction between opposite charged organic molecules. Other factor which affects the solubility of organic acids is solution $\mathrm{pH}$, molecular size. Lower solubility, lower mobility, and high adsorption attraction to membrane is enhance the fouling of large acid molecules $[1,2,33]$.

\section{Damages of membrane fouling}

The restricted use of ED system is due to fouling reason. Due to fouling the most important parameter which is affected is membrane selectivity which causes to enhance energy demand. Increase in electrical hindrance to anion-exchange membranes is due to precipitation of organic anions. Anion-exchange membranes are more prone to fouling due to the organic compounds.

Important types of pollutants which affect the membrane process are colloidal particles. Stay of physical and chemical factors on the membrane surface which causes by the colloidal substance came with water together with concentration growth rate, salinity, flocculation, surface interaction. Performance of membrane decreased with colloidal foulant many of these types found in literature [33].

Anion exchange membranes are not fouled by the presence of sodium carbonate showed by Araya-Farias and Bazinet [34]. Increase in salt concentration in feed water fouling was observed. Cation exchange membranes contact with sodium chloride the precipitation of calcium hydroxide precipitated studies [35].

In membrane chemical failure and fouling enhance due to destruction in mechanical structure. After a running of 2 years operation fouled membrane decrease in $93 \%$ of its toughness and decline in fracture point up to $87 \%$ was revealed by Ghalloussi [11]. ED system utilized in food industry fouled by decomposition mechanism no comprehensive study is available even todays.

Membrane surface was fouled by polarization process due to the $\mathrm{H}+$ ions which is specified by Korngold [36]. Flow velocity reduced due to enhancement of colloid concentration and current density.

\section{Prevention or removal of membrane fouling}

To lesson ED membrane fouling much attention is paid. To study this many procedures developed feed solution pre-treatment, process condition optimization, properties of membrane, cell compartments turbulence. To clean the surface of membrane different methods utilized physical and chemical. Many factors tell which process is utilized for chemical cleaning the most important parameter is type of membrane, intensity of pollution, and type of pollutants. For surface cleaning of membrane, the chemicals recommended by manufacture are high and low strength acids, alkali, complex agents (EDTA), enzymes, detergents and disinfectants $(\mathrm{NaCl}, \mathrm{H} 2 \mathrm{O} 2)$. To overcome membrane fouling operation condition is considered further to consider these strategies needed more chemicals and working equipment which enhance the cost of operation [37]. Physical mode of operation for membrane having driving force pressure surface cleaning is done by vibration, air sparge flushing, back washing and $\mathrm{CO} 2$ back permeating. Replacement method to clean membrane surface effectively is ultrasound [38].

Colloids mostly found in natural water are clay, organic deposits, carbon, dust, iron and aluminum hydroxide. To lessen the colloidal pollution chemical cleaning, Pre-filtration, cross flow is utilized. The movement towards the foulants is due to the electrical potential caused by difference in surface charged and electrical conductivity. Increase in resistance is due to the accumulation of the foulants on membrane surface. With the help of alternative electric current, the accumulated foulants removed. Presence of gel layer at ion exchange membrane surface irregularity occurs with the help of pulsed electric fields in ED process [37].

ED membrane fouling due to organic is the presence of humic matters. Disintegration of organic anions on anion exchange membrane as humic acid. Puncture of small organic anions into membrane holding it inside the membrane and caused membrane fouling. Electrical resistance enhances more rapidly due to this reason. Pre-treatment is the necessary step to stop this effect through other detergents. To lesson these affects, different studies recently zeta potential control and pulsed voltage. Membrane structure is damaged by acid-base, mechanical cleaning [39]. Anion exchange membrane surface fouled by sedimentation of negatively charged humate in ED process. ED system sodium chloride solution having $100 \mathrm{mg} / \mathrm{L}$ was used. Mobility of charged ions increase in fouling layer due to the pulsed electrical fields and ED cell electrical resistance reduced. Factors on which fouling of membrane depends are feed water specification, membrane characteristic, foulant's physical and chemical properties (Table 3) [37].

Cation exchange membrane affected by fouling in ED process used for treating model solution with composition in calcium and carbonate was reported by Bazinet and Araya-Farias [35]. It was revealed that no fouling happened at concentration of 400 to $800 \mathrm{mg} / \mathrm{L}$ of $\mathrm{CaCl} 2$ with no carbonate. Deposition was found only at $400 \mathrm{mg} / \mathrm{L}$ $\mathrm{CaCl} 2$ with carbonate. Buffering capacity of the carbonate was given as reason of this difference. System is affected by buffering capacity with and without sodium carbonate [35]. Both researchers in 2006 study found that fouling could be seen on membrane when it was brought in contact with solution of concentration 400, 800 and $1600 \mathrm{mg} / \mathrm{L}$ calcium chloride with sodium carbonate. It was depicted that fouling on the surface of anionic membrane exists in two forms, either cubic or crystalline material. The conductivity and thickness of membrane was not drastically affected by fouling and membrane could get rid of fouling by soaking with $\mathrm{HCl}$ [35]. Fouling caused by biomass was studied by Bernardes [40]. Microorganisms such as algae, bacteria, fungi in feed water produce biomass and thin layer of fouling is formed on the surface of membrane. Microorganisms could be destroyed by sterilization process. Degradation of polymer membrane by hydrolysis is caused by the biological fouling.

In brackish water desalination industry natural organic matter is 


\begin{tabular}{|c|c|c|c|c|}
\hline Types of Foulant & Definition & Foulants formula & Charge properties & Cleaning methods \\
\hline Scale & $\begin{array}{l}\text { Precipitates of less soluble salts } \\
\text { in the solution }\end{array}$ & $\mathrm{CaCO}_{3}, \mathrm{CaSO}_{4}, 2 \mathrm{H}_{2} \mathrm{O}, \mathrm{BaSO}_{4}, \mathrm{SRSO}_{4}, \mathrm{SiO}_{2}$ & Non & $\begin{array}{l}\text { 1. } \mathrm{pH} \text { adjustment } \\
\text { 2. Use of citric acid or EDTA }\end{array}$ \\
\hline Colloids & $\begin{array}{l}\text { Stack suspended membrane } \\
\text { surfaces }\end{array}$ & $\mathrm{SiO}_{2}, \mathrm{Fe}(\mathrm{OH})_{3}, \mathrm{Al}(\mathrm{OH})_{3}, \mathrm{Cr}(\mathrm{OH})_{3}$ & Negative & $\begin{array}{l}\text { 1. Pretreatment with MF, UF, higher flow rate } \\
\text { 2. } \mathrm{pH} \text { adjustment }\end{array}$ \\
\hline Organics & $\begin{array}{l}\text { Adsorption of organic species to } \\
\text { membrane surfaces }\end{array}$ & $\begin{array}{l}\text { Macromolecules, Proteins, whey, } \\
\text { polyelectrolytes, humate }\end{array}$ & Negative & $\begin{array}{l}\text { 1. Pretreatment with MF, UF, activated } \\
\text { carbon } \\
\text { 2. Clean with } \mathrm{NaOH}\end{array}$ \\
\hline
\end{tabular}

Table 3: Varies types of Foulants and cleaning methods used in ED system.

another cause of membrane fouling and in order to get rid of fouling caused by natural organic matter current flow direction is reversed periodically. The method in which current direction is reversed is called EDR and it is similar to ED just polarity of electrodes is reversed. To accomplish EDR completely some pre-treatment is required [41-46].

\section{Conclusion}

ED process has been found reliable treatment method for waste water since more than half-a-century. In comparison to other separation techniques such as reverse osmosis, ultra-filtration, nano-filtration and ion exchange, ED has shown more benefits. Some of the advantages are as follows: no need of osmotic pressure, no additional chemical requirement, high quality product, environment friendly. The main demerit of ED process is membrane fouling which causes increase in membrane resistance, flux decline, decreases ions migration yield and high level of polarization.

ED process can help in recycling of reuse valuable products and it has regarded as an important technique for sustainable development because it is an environment friendly process. Its driving force is electric potential difference and thus biomass and organic materials will remain in product stream. EDR could be used to prevent fouling and it is more efficient technique. More research is required for improvement of ED process and for developing new cleaning methods in order to prevent fouling.

\section{References}

1. Ashrafi $O$, Yerushalmi L, Haghighat $F$ (2015) Wastewater treatment in the pulp-and-paper industry: A review of treatment processes and the associated greenhouse gas emission. J Environ Manag158: 146- 157.

2. American Water Works Association (Ed) (1995) Electrodialysis and electrodialysis reversal: M38. J Am Water Works Assoc 38.

3. Caprarescu S, Purcar V, Vaireanu DI (2012) Separation of copper ions from synthetically prepared electroplating wastewater at different operating conditions using electrodialysis. Sep Sci Technol 47: 2273-2280.

4. Khan MI, Luque R, Akhtar S, Shaheen A, Mehmood A, et al. (2016) Design of anion exchange membranes and electrodialysis studies for water desalination. Materials 9: 365.

5. Strathmann $\mathrm{H}$ (2010) Electrodialysis, a mature technology with a multitude of new applications. Desalination 264: 268-288.

6. Shaposhnik VA, Kesore K (1997) An early history of electrodialysis with permselective membranes. J Memb Sci 136: 35-39.

7. Mohammadi T, Razmi A, Sadrzadeh M (2004) Effect of operating parameters on $\mathrm{Pb} 2+$ separation from wastewater using electrodialysis. Desalination 167: 379-385.

8. Oztekin E, Altin S (2016). Wastewater treatment by electrodialysis system and fouling problems. Turkish Online Journal of Science \& Technology 6 .

9. Luiz A, Spencer E, McClure DD, Coster HG, Barton GW, et al. (2018) Membrane selection for the desalination of bio-refinery effluents using electrodialysis. Desalination 428: 1-11.

10. Xu T (2005) lon exchange membranes: state of their development and perspective. J Memb Sci 263: 1-29.
11. Dorfner K, Walter de G, Ghalloussi R, Garcia-Vasquez W (2011) Ageing of ion-exchange membranes used in electrodialysis: Investigation of static parameters, electrolyte permeability and tensile strength. Sep Purif Technol 80: 270-275.

12. Nasef MM, Hegazy ESA (2004) Preparation and applications of ion exchange membranes by radiation- induced graft copolymerization of polar monomers onto non-polar films. Prog Polym Sci 29: 499- 561.

13. Kickelbick $\mathrm{G}$ (2003) Concepts for the incorporation of inorganic building blocks into organic polymers on a nanoscale." Progress in Polymer Science 28: 83-114.

14. Gilman JW (1999) Flammability and thermal stability studies of polymer layered-silicate (clay) nanocomposites1. Applied clay science 15: 31-49.

15. Zanetti M, Lomakin (2000) Polymer layered silicate nanocomposites Macromolecular Materials and Engineering 279: 1-9.

16. Armes S (1995) Electrically conducting polymer colloids. Polymer News 20 233-237.

17. Sakata T, Hashimoto K, Hiramoto M (1990) New aspects of electron transfer on semiconductor surface: dye-sensitization system. J Phys Chem 94: 3040-3045.

18. Takada J, Awaji H, Koshioka M, Nakajima A, Nevin WA (1992) Organicinorganic multilayers: A new concept of optoelectronic material. Appl Phys Let 61: 2184-2186.

19. Mitzi DB (2001) Thin-film deposition of organic- inorganic hybrid materials. Chemistry of Materials 13: 3283-3298.

20. Mauritz KA, Mountz D, Reuschle DA, Blackwell R (2004) Self-assembled organic/inorganic hybrids as membrane materials. Electrochimica Acta 50: 565-569.

21. Zou J, Zhao Y, Shi W (2004) Preparation and properties of proton conducting organic-inorganic hybrid membranes based on hyperbranched aliphatic polyester and phosphoric acid. J Memb Sci 245: 35-40.

22. Bauer B, Gerner F, Strathmann H (1988) Development of bipolar membranes. Desalination 68: 279-292.

23. Xu T (2001) Development of bipolar membrane-based processes. Desalination 140: $247-258$.

24. Lee LT, Dege GJ, Liu KJ (1977) High performance, quality controlled bipolar membrane, Google Patents.

25. Mueller H, Puetter H (1987) Production of bipolar membranes, US Patent No 4,670,125 Washington, DC: US Patent and Trademark Office.

26. Gupta B, Chapiro A (1989) Preparation of ion-exchange membranes by grafting acrylic acid into pre- irradiated polymer films-1. Grafting into polyethylene. Eur Polym J 25: 1137-1143.

27. Tongwen X (2002) Electrodialysis processes with bipolar membranes (EDBM) in environmental protection- a review. Resour Conserv Recycl 37: 1-22.

28. Mani K (1991) Electrodialysis water splitting technology. Journal of membrane science 58: 117-138.

29. Jimbo T, Higa M, Minoura N, Tanioka A (1998) Surface characterization of poly (acrylonitrile) membranes graft-polymerized with ionic monomers as revealed by potential measurement. Macromolecules 31: 1277-1284.

30. Takagi R, Nakagaki M (2003) Ionic dialysis through amphoteric membranes Sep Purif Technol 32: 65-71.

31. Azechi S (1970) A numerical analysis of permselectivity between two ions having the same electric charge on the basis of mass transfer model across ion-exchange membrane. Bull Soc Sea Water Sci Jpn 24: 25-54. 
Citation: Akhter M, Habib G, Qamar SU (2018) Application of Electrodialysis in Waste Water Treatment and Impact of Fouling on Process Performance. J Membr Sci Technol 8: 182. doi: 10.4172/2155-9589.1000182

32. Lindstrand V, Jönsson AS, Sundström G (2000) Organic fouling of electrodialysis membranes with and without applied voltage. Desalination 130: 73-84.

33. Bukhovets A, Eliseeva T, Oren $Y$ (2010) Fouling of anion-exchange membranes in electrodialysis of aromatic amino acid solution. J Memb Sci 364: 339-343.

34. Araya FM, Bazinet L (2006) Electrodialysis of calcium and carbonate highconcentration solutions and impact on membrane fouling. Desalination 200: 624 .

35. Bazinet L, Araya FM (2005) Effect of calcium and carbonate concentrations on cationic membrane fouling during electrodialysis. Curr Opin Colloid Interface Sci 281: 188-196.

36. Korngold E, De Körösy F, Rahav R, Taboch MF (1970) Fouling of anionselective membranes in electrodialysis. Desalination 8: 195-220.

37. Lee HJ, Moon SH, Tsai SP (2002) Effects of pulsed electric fields on membrane fouling in electrodialysis of $\mathrm{NaCl}$ solution containing humate. Sep Purif Technol 27: 89-95.

38. Wang Q, Yang P, Cong W (2011) Cation-exchange membrane fouling and cleaning in bipolar membrane electrodialysis of industrial glutamate production wastewater. Sep Purif Technol 79: 103-113.

39. Chang DI, Choo KH, Jung JH, Jiang L, Ahn JH, et al. (2009) Foulant identification and fouling control with iron oxide adsorption in electrodialysis for the desalination of secondary effluent. Desalination 236: 152-159.
40. Bernardes AM, Rodrigues MAS, Ferreira JZ (2013) Electrodialysis and water reuse: novel approaches. Springer Science \& Business Media.

41. Bouhidel KE, Rumeau M (2004) lon-exchange membrane fouling by boric acid in the electrodialysis of nickel electroplating rinsing waters: generalization of our results. Desalination 167: 301-310.

42. Guo H, Xiao L, Yu S, Yang H, Hu J, et al. (2014) Analysis of anion exchange membrane fouling mechanism caused by anion polyacrylamide in electrodialysis. Desalination 346: 46-53.

43. Koter S, Warszawski A (2000) Electromembrane processes in environment protection. Pol J Environ Stud 9: 45-56.

44. Mondor M, Ippersiel D, Lamarche F, Masse L (2009) Fouling characterization of electrodialysis membranes used for the recovery and concentration of ammonia from swine manure. Bioresource technology 100: 566-571.

45. Nagarale RK, Gohil GS, Shahi VK (2006) Recent developments on ionexchange membranes and electro-membrane processes. Adv Colloid Interface Sci 119: 97-130.

46. Ruiz B, Sistat P, Huguet P, Pourcelly G, Araya FM, et al. (2007) Application of relaxation periods during electrodialysis of a casein solution: impact on anionexchange membrane fouling. J Memb Sci 287: 41-50. 